\title{
Perspectives from the Patient and the Healthcare Professional in Multiple Sclerosis: Social Media and Patient Education
}

\author{
Daniel Kantor · Jeremy R. Bright · Jeri Burtchell
}

Received: August 18, 2017 / Published online: December 14, 2017

(C) The Author(s) 2017. This article is an open access publication

\begin{abstract}
A diagnosis of multiple sclerosis (MS) is life-altering. Because the course of MS is heterogeneous, patients may face uncertainty in terms of long-term physical and cognitive challenges, potential loss of employment, and the risk of social isolation. Patients often turn to the Internet and social media for information about MS and its management, and to seek out fellow patients and support groups. Here, we examine the use of social media and the Internet among patients with MS, considering its impact on patient education. We consider the access that these conduits provide not only to other patients with MS but also to a wealth of diseaserelated information online. These themes are further illustrated with first-hand experiences of the patient author and her physician. We also
\end{abstract}

Enhanced content To view enhanced content for this article go to http://www.medengine.com/Redeem/76FC F060777D02D5.

D. Kantor $(\square)$

Florida Atlantic University, Boca Raton, FL, USA

e-mail: info@KantorNeurology.com

J. R. Bright

Oxford PharmaGenesis, Oxford, UK

J. Burtchell

HealthiVibe, LLC, Arlington, VA, USA

J. Burtchell

Partners in Research, East Palatka, FL, USA explore the impact of the Internet and social media on the education and support of patients with MS from the healthcare professional's (HCP's) perspective, including opportunities for HCPs to promote disease education among their patients, and the advantages that arise from patients being better informed about their disease. The rise of the Internet and social media has changed the patient experience, helping patients to support each other, to educate themselves proactively about their condition, and to participate more actively in decisions relating to disease management than perhaps was the case historically.

Funding Novartis Pharmaceuticals Corporation.

Keywords: Internet; Multiple sclerosis; Patient education; Patient voice; Social media; Web

\section{INTRODUCTION}

The impact of multiple sclerosis (MS) is often profound. In addition to being at risk of physical disability, patients may experience changes in cognition and feel fatigued, anxious, or depressed $[1,2]$. Together, these aspects of MS can lead to changes in employment status, reduced standard of living, and withdrawal from social and leisure activities [1]. Encouragingly, treatment options have proliferated in recent years, so although treatment decisions 
can be complex [3], patients are much better served now than they were only a few years ago. Through the Internet and social media, patients with MS can access a wealth of information about the diagnosis and its various treatment options, enabling them to participate in the therapeutic decision-making process.

In this article, we provide insights directly from a patient with MS and a healthcare professional (HCP) into the ways in which use of the Internet and social media by patients with MS has influenced their education and support over the past two decades. From the standpoint of promoting patient education, we consider the impact of virtually instant global access both to information and to individuals affected by MS, on patients with MS, and on the HCPs who treat them. Much of the HCP-related research cited pertains to physicians, but we use the term HCP for both physicians and other professionals caring for patients with MS.

\section{METHODS}

This article offers qualitative, case study-based insights from the patient and HCP authors, both of whom are from North America. As in our accompanying article, which examines the impact of social media and the Internet on aspects of participatory medicine in MS, the HCP's perspective in this article is provided by an MS specialist, Daniel Kantor, MD, FAAN, past President of the Florida Society of Neurology, President of the Medical Partnership 4 MS, Chief Medical Correspondent for MSWorld, and an active member of the Multiple Sclerosis Foundation's Medical Advisory Board and the Multiple Sclerosis Association of America's Healthcare Advisory Council. The patient's perspective is provided by Jeri Burtchell, a clinical trials awareness activist, MS patient advocate, founder of Partners in Research, and Director of Patient Initiatives at HealthiVibe, LLC. These perspectives are drawn together in the context of published research by Jeremy Bright, a medical writer at Oxford
PharmaGenesis with a special interest in MS. The article also includes some of Jeri's experiences since being diagnosed with MS in 1999, 3 months after the onset of symptoms.

The patient's perspective was provided as follows: a Novartis employee drafted a set of questions for use in a subsequent interview with the patient author (Jeri Burtchell). During the interview, Jeri's responses to these questions were recorded. Unedited and non-paraphrased quotes were taken directly from the recordings and used as appropriate throughout the manuscript. The HCP's perspective was provided directly by the HCP author, Daniel Kantor. To the best of our knowledge, this is the first time that this "patient-HCP dyad" approach has been used to explore patient and HCP perspectives regarding the impact of the Internet and social media on patients with MS. Adopting this novel approach enabled us to gain detailed and direct insights, not previously reported, into a number of key issues.

The patient and HCP perspectives described in this article were provided by individuals from the USA. As the insights yielded by this approach are specific to the authors' personal experiences, the generalizability of the findings may be limited as they may not represent those of the wider MS population and other HCPs. In order to minimize any bias, a separate literature search was conducted to identify relevant articles that contextualized the themes identified by the patient and HCP authors. Supporting published references and online resources relating to Internet and social media use in MS were identified using MEDLINE and Google Scholar, with the following search strings: "multiple sclerosis[Title/Abstract] AND social media[Title/abstract]" and "multiple sclerosis[Title/Abstract] AND Internet[Title/Abstract]".

\section{Compliance with Ethics Guidelines}

This article does not contain any new studies with human or animal subjects performed by any of the authors. 


\section{LIVING WITH MULTIPLE SCLEROSIS}

In coping with their disease, individuals with MS may face many challenges, including changes in physical ability, cognition, employment status, and effects on their mental health and well-being. Without treatment, patients with MS accumulate moderate levels of disability (Disability Status Scale [DSS] score of 3) on average within 8 years of diagnosis, and need assistance with walking (DSS score of 6) within 9-15 years of diagnosis [4]. In addition, 40-65\% of patients with MS have some degree of cognitive impairment, primarily involving learning, memory, and attention, as well as executive functions such as organization, decision-making, and problem-solving $[5,6]$. A cross-sectional study of European patients with MS conducted in 2005 revealed unemployment rates of between $60 \%$ and $75 \%$ [7], and a Danish retrospective study published in 2009 found that retirement occurred about 14 years earlier among patients with MS than among matched control individuals [8]. Compared with the general population, lifetime prevalence for a variety of psychiatric disorders, including major depressive disorder, is elevated among individuals with MS, and suicide may be at least twice as common [9]. The factors contributing to the development of depression in MS are complex. However, lower educational level, greater disability severity, being retired owing to MS or being unemployed, having progressive-relapsing MS (now termed primary progressive MS with activity), one or more comorbidities, and clinically significant fatigue are all associated with increased risk of depression, as are a number of modifiable lifestyle factors [10]. Furthermore, a significant minority of patients with MS are confined to their homes [11].

In considering the impact of the Internet and social media on patients with MS, Jeri and Dr. Kantor's perspectives can be grouped into four major themes: (1) managing MS before the advent of the Internet and social media; (2) disease awareness in the age of social media; (3) treatment awareness in the age of social media; and (4) the quality of information available on social media. In the following sections we present physician and patient perspectives on each of these themes and contextualize them in terms of the available literature. A further section outlines general use of the Internet and social media, including by patients with MS.

\section{MULTIPLE SCLEROSIS BEFORE THE ADVENT OF THE INTERNET AND SOCIAL MEDIA}

\section{Patient's Perspective}

Jeri was diagnosed with MS in 1999, 3 months after the onset of symptoms.

"I awoke one morning in January 1999 and my left foot was numb. I shrugged it off, thinking it was asleep, but it never woke back up again, and within 2 weeks the numbness had spread from my left foot to my right and worked its way up to my waist. During that time I was getting progressively weaker until every step I took felt like I was forcing my way through mud."

Patients' experiences of receiving a diagnosis of MS vary a great deal, and although these experiences seem to have improved recently, poor levels of support and information were still being reported in 2007 [12]. Jeri received neither appropriate support nor helpful information following her diagnosis.

"I received no information about MS and was sent home to await a visit from an inhome nurse who would teach me how to inject myself. The medication came with a hotline number to reach a nurse if I had any questions about my medication. I called the regional chapter of the National MS Society to find out anything I could. They added me to their mailing list and I began receiving their newsletters and quarterly magazine. I was disappointed to learn there was no local support group in my area."

The Internet was still in its infancy when Jeri received her MS diagnosis, and she was frustrated by the difficulty of sourcing information about the disease. 


\begin{abstract}
"My mother put me in touch with a former co-worker who was diagnosed with MS 10 years prior. We had a long talk on the phone, but her MS was completely different from mine. Although we shared a common disease, I felt like we were speaking two different languages."

"I visited the library to learn more, but none of the books they had on neurological conditions were recent. When I was able to get to a larger town, I would seek out a bookstore like Barnes \& Noble to try and find more current literature about MS."

"Although the Internet was available at the time, it was cost prohibitive and I didn't have a decent computer, anyhow."
\end{abstract}

During this pre-Internet era, patients with physical and cognitive problems may have been particularly disadvantaged by the limited ability to have clinic visits and to recall details about their clinical encounters [13]. In terms of overall well-being, patients may also have been disadvantaged by the more limited opportunities for social interaction that existed before the arrival of the Internet and social media. Patients with MS can become isolated, removed from society [11] and the workplace [7], and can lose the opportunity to engage in social interactions. Indeed, Jeri encountered these issues as her MS progressed. Experiencing three or four relapses annually for the first 7 years, Jeri often had to use a walker or wheelchair for months at a time.

"I felt isolated and closed in. The more my disease robbed from me, the more introverted and depressed I became. I was forced to close my print shop I'd had since 1990, due to my failing health. Interacting with my customers had been my main source of social interaction, so when my business closed I became even more isolated."

\section{HCP's Perspective}

Dr. Kantor described how, before the advent of the Internet, medical knowledge was concentrated among HCPs: they had undergone advanced training and had continued their lifetime education through Continuing Medical Education courses, by reading journal articles and textbooks, and by interacting with other HCPs in settings both formal (such as conferences) and informal (such as hallway conversations). It was extremely time consuming for a patient to remain as updated as their HCP on recent advances. Interactions between HCPs and patients occurred only in face-to-face clinical office visits and in group settings, when an HCP would address an MS support group.

\section{PATIENTS WITH MULTIPLE SCLEROSIS, THE INTERNET, AND SOCIAL MEDIA}

When Internet search engines first became widely available in the early 1990s, a search of the World Wide Web (Web) for "multiple sclerosis treatment" would probably have yielded few or no results; whereas today, putting this term into a search engine yields more than 29 million results. As well as providing access to such a colossal repository of information, the Web is the conduit for social media activities (ideas, group messages, personal messages, images, videos, etc.). Social media enable users to create and communicate information and to participate in social and professional networking $[14,15]$ and there is a long history of patients turning to the Internet and online communities for advice and support [16]. An early example is Bob Willmot's "kneeboard", an online forum created in 1996 specifically for patients with knee injuries, allowing them to discuss their injuries and recovery with others [17]. With increasing access to the Internet, the number of these online communities has risen rapidly. A Pew Research Center survey found that $74 \%$ of adults in the USA who used the Internet in 2014 participated in social media networks [18]. Slightly more women than men were networking (76\% vs 72\%) [18] and online activity was related to age and income [19]. Facebook was the most popular site $(71 \%$ of online adults); LinkedIn, Pinterest, Instagram, and Twitter registered $23-28 \%$ usage (Table 1) [18-24]. Globally, this equates to nearly 
Table 1 Summary of survey data

\begin{tabular}{|c|c|c|}
\hline $\begin{array}{l}\text { Survey of online } \\
\text { activity }\end{array}$ & $N$ & Findings \\
\hline \multicolumn{3}{|l|}{ General population } \\
\hline $\begin{array}{l}\text { Pew Research } \\
\text { Center (2014) } \\
{[18]}\end{array}$ & 5112 & $\begin{array}{l}74 \% \text { of US adults online } \\
\text { used social media } \\
71 \% \text { used Facebook; } \\
23-28 \% \text { used LinkedIn, } \\
\text { Pinterest, Instagram, or } \\
\text { Twitter }\end{array}$ \\
\hline $\begin{array}{l}\text { Pew Research } \\
\text { Center (2014) } \\
{[19]}\end{array}$ & 5512 & $\begin{array}{l}\text { Internet usage was related to } \\
\text { age, educational } \\
\text { attainment, and } \\
\text { household income }\end{array}$ \\
\hline $\begin{array}{l}\text { Study in USA } \\
(2006)[20]\end{array}$ & 2390 & $\begin{array}{l}75 \% \text { of the general public } \\
\text { used the Internet }\end{array}$ \\
\hline \multicolumn{3}{|l|}{ Patients with MS } \\
\hline $\begin{array}{l}\text { Study in } \\
\text { Germany } \\
(2009-2010) \\
{[21]^{\mathrm{a}}}\end{array}$ & 586 & $\begin{array}{l}94 \% \text { of patients with MS } \\
\text { had access to the Internet } \\
\text { Patients who used the } \\
\text { Internet most frequently } \\
\text { were most likely to be } \\
\text { receptive to using new } \\
\text { forms of electronic } \\
\text { communication with } \\
\text { HCPs }\end{array}$ \\
\hline $\begin{array}{l}\text { NARCOMS } \\
\text { (2011) [22] }\end{array}$ & 8586 & $\begin{array}{l}86 \% \text { of patients with MS } \\
\text { had accessed the Internet } \\
\text { or used e-mail } \\
\text { More than } 60 \% \text { of these } \\
\text { patients accessed the } \\
\text { Internet several times a day }\end{array}$ \\
\hline $\begin{array}{l}\text { Study in USA } \\
(2006)[20]\end{array}$ & 2390 & $\begin{array}{c}93 \% \text { of respondents with } \\
\text { MS used the Internet }\end{array}$ \\
\hline $\begin{array}{l}\text { Study in UK } \\
(2010) \text { [23] }\end{array}$ & & $\begin{array}{l}92 \% \text { of patients with MS } \\
\text { reported that they used } \\
\text { the Internet } \geq 3 \text { times/ } \\
\text { week }\end{array}$ \\
\hline
\end{tabular}

Table 1 continued

\begin{tabular}{lll}
\hline $\begin{array}{l}\text { Survey of online } \\
\text { activity }\end{array}$ & $N \quad$ Findings \\
\hline
\end{tabular}

Disease awareness among patients with MS

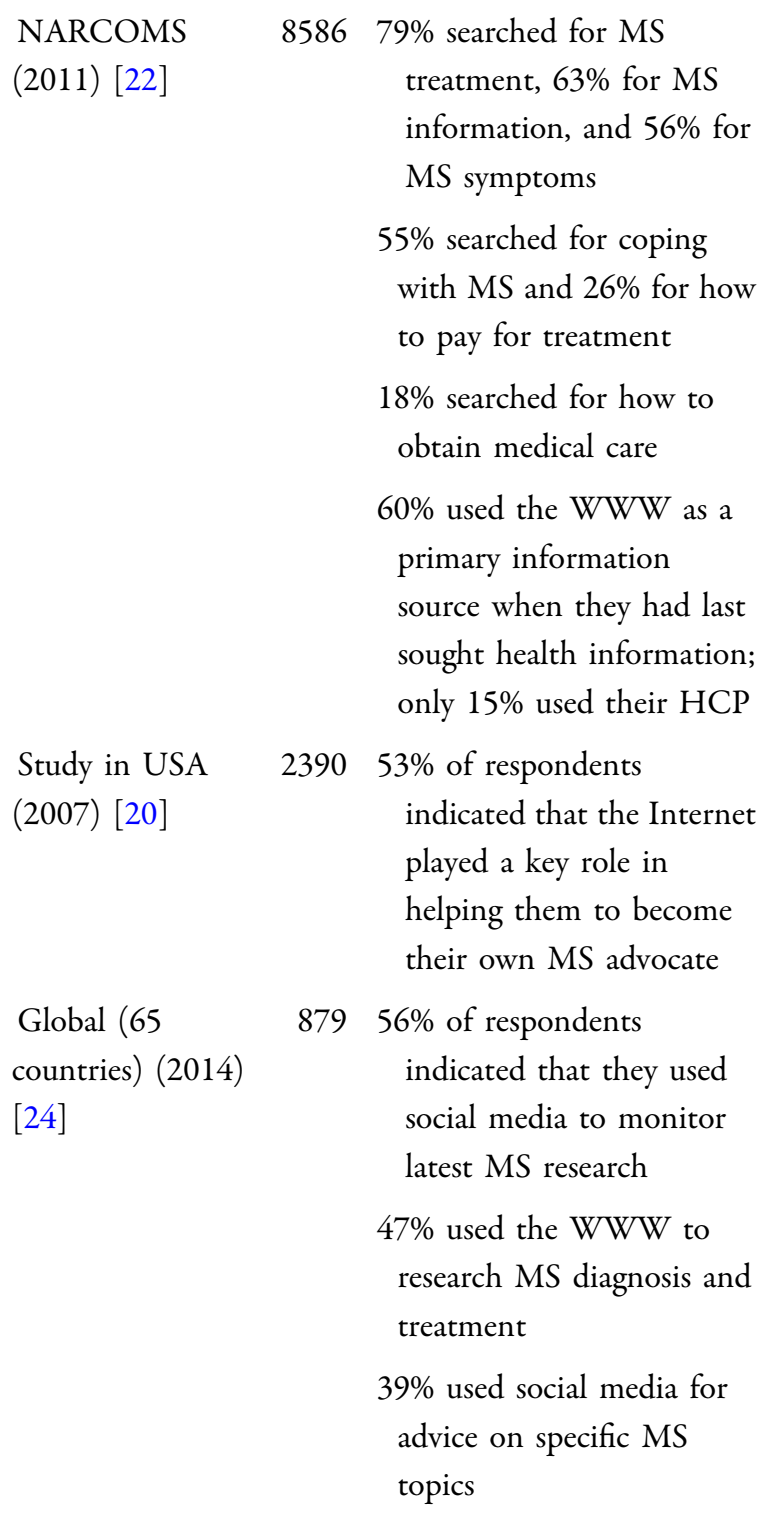

HCP healthcare professional, $M S$ multiple sclerosis, NARCOMS North American Research Committee on Multiple Sclerosis, $W W W$ World Wide Web

${ }^{a}$ Multiple Sclerosis Center Dresden (Dresden, Germany), Multiple Sclerosis Center Stuttgart (Stuttgart, Germany), and several neurological outpatient centers of NeuroTransData GmbH (Neuburg, Germany) 
1 billion daily users of Facebook and 328 million active monthly users of Twitter in 2017 $[25,26]$.

For patients with MS, social media may help them to understand and manage both their disease and their treatment options. Considering the online activities of patients with MS, a survey conducted from 2009 to 2010 in outpatient clinics in Germany [21], as well as a 2011 survey of 8586 patients with MS in the USA and Canada (the North American Research Committee on Multiple Sclerosis [NARCOMS] registry) [22], found that most patients (86-94\%) had access to the Internet or e-mail, and that $60-71 \%$ accessed it at least once a day. Similarly, a UK survey from 2010 reported that $92 \%$ of people with MS used the Internet three times or more per week [23], and a 2007 US survey of 2390 patients with MS reported Internet use by $93 \%$ of participants, compared with $75 \%$ of the general population [20]. Notably, the German survey found that patients who used electronic media regularly were more likely to accept this media type for communication with HCPs, compared with patients who used electronic media infrequently [21].

\section{DISEASE AWARENESS IN THE AGE OF SOCIAL MEDIA}

\section{Patient's Perspective}

Newly diagnosed individuals can benefit from the targeted provision of online information, because it can improve their knowledge of MS and satisfaction with their care [27]. As online content has accrued, patients with MS have increasingly used the Internet both to source medical information and to communicate within the MS community [28, 29]. When asked about the most recent time that they sought information, $60 \%$ of patients in the 2011 NARCOMS registry cited the Internet as their first source of information about MS (compared with $15 \%$ seeking information from their HCP) [22]. Similarly, in 2014 it was estimated that $72 \%$ of US and European patients with MS found social media and online resources most helpful for obtaining information about their condition
[30]. The relatively high use of the Internet by patients with MS compared with the general population, combined with the strong interest of these individuals in using online portals and other online technologies to source information about their condition and to communicate with HCPs, suggests that patients with MS may be super-adopters of emerging e-health trends [31-33]. Indeed, receiving a diagnosis of MS had a profound psychological effect on Jeri and she was keen to find out more.

"I remember being terrified and also in deep denial. I didn't even know what MS was-I had it confused with muscular dystrophy."

The Internet and online communities helped Jeri to source much-needed information about her condition and enabled her to connect and share experiences with other patients with MS.

"Sometime during 2002, 3 years after my diagnosis, I got a new computer and connected to the Internet. I researched MS online, but the Internet was so new that finding good sources of information was not easy. I mostly learned through anecdotes and conversations with other patients in online forums. I spoke to someone with MS who my mother knew and, at my urging, she started a support group."

"I had begun working part-time from home, so I honed my online skills in forums for online sellers, eventually venturing out to other parts of the Internet to seek information about my disease."

When individuals in the 2011 NARCOMS registry were asked about the type of information sought online, $79 \%$ nominated treatment for MS and 63\% nominated general information about MS; symptoms of MS (56\%) and coping with MS (55\%) were also actively researched, as were paying for $(26 \%)$ and exploring where to obtain (18\%) medical care [22]. However, the most trusted information source was still an HCP, with $98 \%$ of patients reporting that they trusted a physician somewhat or a lot [22]. In a separate survey of 879 patients from 65 countries that was published in 2014, about half of 
the participants used social media to monitor the latest MS research (56\%) and about half to gather information on diagnosis and treatment (47\%); the most common sources of information were MS organization websites, followed by medical or scientific sites and HCPs (Table 1) [24]. In a 2007 survey of 2390 US patients with MS, $53 \%$ of respondents also revealed that Internet use had helped them to become their own MS advocate [20].

In addition to individual HCPs using social media to educate and advocate for people with MS, institutions have increasingly carved out a presence in the social media sphere. While it seems that some institutional accounts are managed by individuals with little direct knowledge of the needs of patients with MS, others are managed either by HCPs affiliated with the institution or by their delegates. However, Jeri does not recall having been directed to websites or social media accounts by any of the tertiary care centers with which she has been involved. By contrast, advocacy groups such as the National Multiple Sclerosis Society (http://www.nationalmssociety.org) and the Multiple Sclerosis Association of America (mymsaa.org) do seem to have a strong online presence, and Jeri relies heavily on these sites for information.

\section{HCP's Perspective}

As is evident in the literature [34], Dr. Kantor noted that patients with MS are generally considered to be extremely well informed. However, various studies have shown that their information needs and Internet activities vary according to individual characteristics, the length of time since diagnosis, and disease type, stage, and severity [34-38]. Low levels of health literacy are linked to increased risk of adverse health behaviors (e.g., smoking or being overweight or obese) [39], increased healthcare utilization (hospitalizations and emergency room use) $[39,40]$, less participation in health promotion programs, poorer treatment adherence and patient outcomes, and worse overall health status [40]. Among the potential benefits of social media highlighted by Dr. Kantor (Table 2)
Table 2 Potential benefits of social media in health care $[15,42-44]$

Improved physician-patient communication

Increased patient motivation

Timely awareness of important issues

Greater access to accurate health information

Engagement of a large number of patients

Encouragement of debate and exchange of ideas

Improved patient access to health services and social support

Better outcomes

Behavioral change and better treatment adherence/compliance

Reduced healthcare resource usage and overall costs

Public health surveillance

Better-informed treatment decisions

are the abilities to promote health education and to improve health behavior and access to health services among large numbers of patients $[15,41-44]$. Indeed, providing patients who have MS with appropriate information appears to increase their disease-related knowledge [45]. Moreover, access to online information and engagement through social media may influence patients' adherence to treatment and their coping strategies, and lead to greater empowerment and improved clinical outcomes $[21,31,46]$. While the role of social media in supporting patients tends to be positive, both patients and HCPs need to be aware of the potential pitfalls (Table 3 ), such as identifying reliable and trustworthy sources of information (discussed later), concerns about patient confidentiality, and maintaining appropriate patient-HCP relationships (discussed in more detail in the accompanying "Participatory medicine" article).

The findings of a US study from 2014 highlight the need for careful research to ensure that dissemination of information by any particular channel is effective [47]. The study found that 
Table 3 Potential pitfalls of social media in healthcare [13, 42-44, 54, 55]

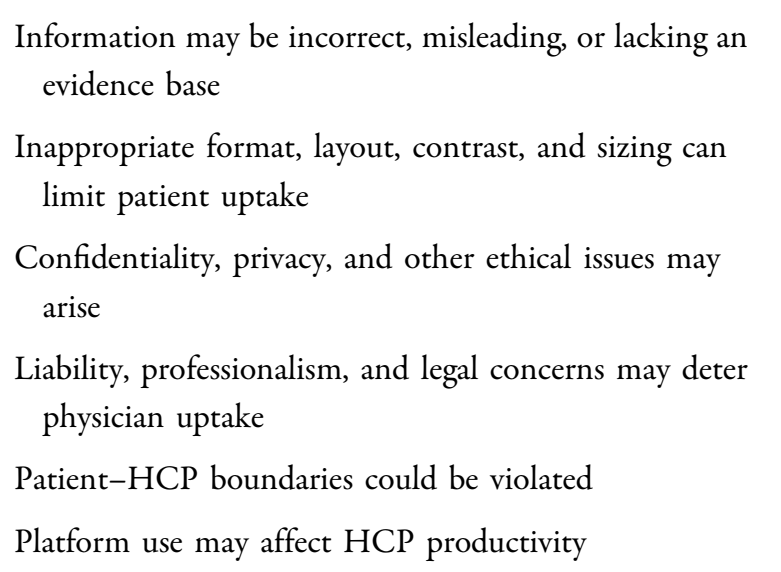

HCP and patient awareness/knowledge of the American Academy of Neurology Clinical Practice Guideline "Complementary and alternative medicine in multiple sclerosis" was not increased by adding novel routes of dissemination (e.g., Facebook, Twitter, YouTube, and LinkedIn) to more traditional routes (e.g., print, e-mail, and Internet-based methods). Traditional dissemination may already have saturated the target audience, or social media may not have been the most appropriate channel for this type of information [47].

Dr. Kantor also noted that programs aimed at modifying health behaviors may be honed by understanding patient concerns garnered from social networking sites. For example, in an Italian study conducted in 2011, patients with MS reported that they trusted social networks because they considered the users (i.e., fellow patients) to be independent of commercial or other interests [28]. Social networks afford HCPs the opportunity to share reliable, high-quality information, and to develop health messages that are more likely to resonate with and be adopted by patients [43], while simultaneously responding to the demand by patients for an interactive communication that is easy to access [48].

There is little published information on the similarities and differences between institutional and individual HCP social media use.
However, Dr. Kantor has noticed that the ways in which some institutions use social media resemble the manner of usage by individual HCPs; these cases are probably attributable to usage by an individual HCP employed by the institution. However, other institutions appear to use social media as a marketing tool to retain current patients and to attract new ones.

\section{TREATMENT AWARENESS IN THE AGE OF SOCIAL MEDIA}

\section{Patient's Perspective}

Patients search for MS-related information online, including drug treatments and side effects, emerging research, new and alternative treatment options, and HCPs' credentials [22, 24, 29, 31, 36, 49]. Jeri also used several online resources to help address her concerns about the potential side effects of medication and to find information about switching treatments.

"I remember a specific incident when my PCP [primary care provider] prescribed an antidepressant. I was afraid to take it because I'd been reading about the side effects on the package insert. I searched on MSWorld [http://www.msworld.org/] for anything I could find about the medication. I also posted that I was about to start taking it and wondered about things like dependency and mood changes. Almost instantly others from around the world were commenting and sharing their experiences, giving me the feedback I needed to make my own decision."

"I noticed people were also sharing about how they were switching MS medications when theirs 'quit working' for them. The next time I saw my neurologist I asked him about switching."

In the 2014 global MS survey, more than one-third of respondents (39\%) reported that they used social media to seek the opinions of others on specific topics [24], which Jeri also noted. 
"I have noticed there is a trend in online use of social media among patients with MS and other chronic conditions that they interact online when seeking advice because they're having problems. Whether it is due to new symptoms and they want to hear how others have dealt with them, or they think something might be an adverse event caused by their medication, online activity among a large portion of those with MS involves finding out what others think about their current crisis situation."

In 2007, after deciding to enroll in a clinical trial, Jeri started a blog to document her experience from the patient's perspective, and continues to contribute regularly to online activities related to MS. Sharing the experiences of other patients with MS can be empowering, giving individuals the confidence to discuss disease management options with their HCP.

"When patients talked about switching medications often they just stated that their current medications were either 'not working' for them anymore, or they were 'fatigued' by the side effects. Some even spoke of 'drug holidays' which intrigued me."

"Delivery method seems to be a big concern among those who are newly diagnosed compared to those who lived through the era where your only choice was injectable."

"Most of these conversations come up when a doctor has said it was time to switch, and the patient is trying to research their choices, or when a patient feels it's time to switch and wants to figure out which drug to pitch to their doctor."

\section{HCP's Perspective}

A major advantage of social media highlighted by Dr. Kantor is the insight it offers into the real-world views held by patients regarding their disease, its treatment, and their care. For example, patient bloggers such as Wheelchair Kamikaze, and numerous contributors to
PatientsLikeMe, have written extensively on topics ranging from the emotional and physical challenges of living with MS through to issues about the pharmaceutical industry [50, 51]. Twitter has also been used to investigate patients' experiences with MS drug therapies [52]. Of a total of 60,037 tweets posted between 2006 and 2014 that mentioned approved MS treatments, almost half contained non-neutral sentiments about treatment, although the most commonly tweeted words related to routes of administration and effects of treatment (including known side effects) [52].

Dr. Kantor also highlighted how patient experiences shared via social media are now being used to answer specific questions relating to MS outcomes. For example, content posted by US patients to Facebook, Twitter, blogs, and online forums in 2013 and 2014 mentioning specific oral, injectable, and intravenous MS treatments was collected and analyzed to understand patients' switching behaviors. Compared with more traditional methods of research (e.g., retrospective analyses of claims databases), this approach provided novel insights into patients' personal experiences of their treatments and common reasons for switching treatments [53].

Given that use of social media has almost certainly led to a patient population that is better informed about current treatment options, Dr. Kantor believes it reasonable to expect that this has also led patients to challenge their HCP's prescribing recommendations more often, further influencing their practice patterns. Patients offering guidance to each other can be beneficial to HCPs, because this reduces the time that HCPs need to commit to educating patients about their disease process and treatment options, and time can be better spent making shared decisions on patient care.

\section{QUALITY OF INFORMATION ON SOCIAL MEDIA}

\section{Patient's Perspective}

A 2009 survey of Internet use among Israeli patients with MS found that most believed that 
information on the Internet was as trustworthy as that in books [36]. By contrast, studies conducted in 2011 showed that North American [22] and Italian [28] patients had concerns about the quality and trustworthiness of information online, and had difficulties in accessing or understanding the information they wanted $[22,28]$. Jeri also raised this concern.

"Finding a way to verify the factual information people were posting was nearly impossible. At first, I would take everything everyone said as fact, or if they provided links to websites that purported to have the miracle cure, etc., I'd get excited and think maybe they were on to something. This would lead to a cycle of getting my hopes up, followed by having them dashed, and finally becoming jaded to anything I read or heard. It would take a while before I would develop the Internet savvy that helped me become a discerning, scrutinizing consumer of the Internet."

However, over time, Jeri learned how to identify reliable sources of information.

"I learned to look for clues and to always question the motives or goals of whatever website I landed on. If they were promoting a 'cure all' product, I knew they were only interested in sales. If articles were surrounded by ads for products that appeared to be 'too good to be true', I would back out. Over time, I began looking for validating sources to corroborate whatever 'facts' were being presented. If the sources included links to published, peer-reviewed white papers or study results, then I was more inclined to trust the content I was reading. But even then, I learned to delve further. If something was written by a person with 'PhD' or ' $\mathrm{MD}^{\prime}$ after their name, it didn't necessarily mean that it was credible. If it was a topic I was seriously interested in, perhaps something controversial like CCSVI [chronic cerebrospinal venous insufficiency] for instance, then I would research the authors' backgrounds as well to see what motivated them."
"Knowing who to trust on the Internet isn't easy, even for people who think they have become savvy at discerning real information from a scam. When in doubt, my best advice would be to speak to your doctor."

The reliability of information is clearly an important issue for many patients: in the Multiple Sclerosis International Foundation (MSIF) 2014 global survey examining information technology use and MS, one-third of patients with MS reported content with 'a scientific or statistical basis' to be the factor that most increased the reliability of MS information; furthermore, some patients verified information independently using public databases such as PubMed [24]. Jeri also adopted an evidencebased approach as her experience in seeking MS-related information increased.

"Writing about MS led me to hone my online research skills, diving deeper into using tools like Google Scholar and learning how to avoid sources that may not have the best information. I learned to trust sources that cited their own sources, began looking for the HON Code symbol on sites, indicating they met the criteria for providing trustworthy health information as laid out by the Health on the Net Foundation."

In the same MSIF leaflet that published these results, guidance was also provided for patients and HCPs on how to get the most from the Internet [24]. It includes a section on how to evaluate the trustworthiness of websites and highlights the importance of checking factors such as who is responsible for the website content, and whether content seems reliable or is presented in an unbiased and easy-to-read format [24].

\section{HCP's Perspective}

Among the potential benefits of social media outlined by Dr. Kantor is the ability to rapidly disseminate accurate, evidence-based healthcare information and educational resources to large numbers of patients and to counter 
inaccurate online material; this is supported by findings from several recent studies [41-43]. Dr. Kantor also highlighted how, in the age of social media, face-to-face interactions remain important, and there may be a need to encourage patients to talk with their HCP about what they have encountered online. Indeed, in a US survey of patients who presented for the first time at an MS clinic between 2003 and 2005, 82\% of individuals with MS had performed web-based searches in preparation for an initial consultation, so it was perhaps surprising that only $36 \%$ of patients who gathered information before their first appointment subsequently discussed it with their HCP [31]; this lack of clinical corroboration highlights the possible pitfalls of potentially unreliable "medical" information. Examples of such unreliable information have been highlighted in various studies, including an expert analysis of 25 French-language Internet sites about MS [54]. All content (collected on a single day in 2014) was deemed to be mediocre and poorly referenced, highlighting the need for HCPs to provide patients with guidance on where to find reliable information online [54]. Access to poor-quality information may be of particular concern when the content relates to a proposed new treatment that lacks an evidence base, such as CCSVI. A 2016 analysis of all YouTube videos relating to CCSVI posted between December 2009 and July 2011 found that most presented a positive or unbalanced view of the treatment, and did not acknowledge the lack of supporting scientific evidence or the possible role of the placebo effect [55].

Web initiatives, such as the Integrating and Deriving Evidence, Experiences and Preferences (IN-DEEP) project, have been developed specifically to counter such issues [56]. Established as part of an Australian-Italian collaboration, IN-DEEP aims to provide accessible and meaningful evidence-based information to patients with MS, relevant to situations that they might encounter in everyday life [56]. In addition, an online community (http://www. smsocialnetwork.com) was established in 2012 to allow Italian patients with MS to exchange information based on sound medical and scientific evidence with each other. All content is overseen by neurologists and psychologists experienced in MS, who intervene if any false or inappropriate medical information is posted $[57,58]$. Dr. Kantor recognizes how initiatives such as these could help to counter the mass of false, misleading, or unsubstantiated information about MS that exists online, although there are time and cost implications associated with such efforts.

\section{CONCLUSIONS}

As identified by Jeri and Dr. Kantor, as well as across different countries in the supporting literature, the rise of social media and the widespread use of healthcare-related information on the Internet in the MS patient community have had a profound impact on the disease area. Individuals with MS are now connected to each other and to sources of information regarding their condition more than ever before. This has enabled patients to educate themselves about their condition, so that they are better informed about MS and its treatment, and has empowered them to take an active role in making decisions about their health care. Social media and the Internet have also allowed HCPs to promote health education and to disseminate accurate medical information more easily, and have enabled HCPs to steer patients towards unbiased peer-reviewed or society-endorsed sources of information online. This is particularly important given the wealth of content that is incorrect, misleading, or lacking an evidence base. At the same time, HCPs have become more aware of the benefits that such platforms can confer in terms of patient education. While HCPs are more aware than they have been historically of the benefits in terms of patient education that such platforms can confer, the time needed to assimilate their use into routine clinical practice may be a limiting factor. Finally, even if the Internet and social media are the sources that patients use most frequently to research their condition, HCPs are still the most trusted sources of healthcare information, and their contributions to online media are invaluable. 


\section{ACKNOWLEDGEMENTS}

Editorial and medical writing support of the manuscript and the journal's article processing charges were funded by Novartis Pharmaceuticals Corporation. The authors acknowledge Ian Williams of Oxford PharmaGenesis, Oxford, UK, who provided editorial and medical writing support, and Kathleen Hawker, formerly of Novartis Pharmaceuticals Corporation (East Hanover, NJ, USA), who reviewed the article during the early stages of development and conducted the interview with Jeri Burtchell. In addition, Novartis reviewed the final draft of the manuscript for scientific accuracy only. All named authors meet the International Committee of Medical Journal Editors (ICMJE) criteria for authorship for this manuscript, take complete responsibility for the integrity of the work as a whole, and have given final approval for the version to be published.

Disclosures. Daniel Kantor has received research support from Novartis and speaking/consulting honoraria, not related to this publication. Jeremy R. Bright is an employee of Oxford PharmaGenesis. Jeri Burtchell has acted as a consultant for Janssen, Lilly, Louisiana Public Health Institute, Novartis, Rutgers University, and Vanderbilt University, and has received fees for speaking from ERT, Janssen, Lilly, and Novartis. She is the founder of Partners in Research and Director of HealthiVibe, LLC. As an employee of HealthiVibe, LLC, she has worked on projects with many pharmaceutical companies including Novartis. She also serves on the patient advisory boards of CureClick and MS SoftServe, Inc.

Compliance with Ethics Guidelines. This article does not contain any new studies with human or animal subjects performed by any of the authors.

Data Availability. Data sharing is not applicable to this article as no data sets were generated or analyzed during the current study.

Open Access. This article is distributed under the terms of the Creative Commons
Attribution-NonCommercial 4.0 International License (http://creativecommons.org/licenses/ by-nc/4.0/), which permits any noncommercial use, distribution, and reproduction in any medium, provided you give appropriate credit to the original author(s) and the source, provide a link to the Creative Commons license, and indicate if changes were made.

\section{REFERENCES}

1. Hakim EA, Bakheit AM, Bryant TN, et al. The social impact of multiple sclerosis-a study of 305 patients and their relatives. Disabil Rehabil. 2000;22:288-93.

2. Zwibel HL, Smrtka J. Improving quality of life in multiple sclerosis: an unmet need. Am J Manag Care. 2011;17(Suppl 5):S139-45.

3. Farber RS, Sand IK. Optimizing the initial choice and timing of therapy in relapsing-remitting multiple sclerosis. Ther Adv Neurol Disord. 2015;8:212-32.

4. Weinshenker BG, Bass B, Rice GP, et al. The natural history of multiple sclerosis: a geographically based study. I. Clinical course and disability. Brain. 1989;112:133-46.

5. Holland NJ, Schneider DM, Rapp R, Kalb RC. Meeting the needs of people with primary progressive multiple sclerosis, their families, and the health-care community. Int $\mathrm{J}$ MS Care. 2011;13:65-74.

6. Jongen PJ, Ter Horst AT, Brands AM. Cognitive impairment in multiple sclerosis. Minerva Med. 2012;103:73-96.

7. Kobelt G, Berg J, Lindgren P, Fredrikson S, Jonsson B. Costs and quality of life of patients with multiple sclerosis in Europe. J Neurol Neurosurg Psychiatry. 2006;77:918-26.

8. Pfleger CC, Flachs EM, Koch-Henriksen N. Social consequences of multiple sclerosis (1): early pension and temporary unemployment-a historical prospective cohort study. Mult Scler. 2010;16:121-6.

9. Minden SL, Feinstein A, Kalb RC, et al. Evidencebased guideline: assessment and management of psychiatric disorders in individuals with MS: report of the Guideline Development Subcommittee of the American Academy of Neurology. Neurology. 2014;82:174-81. 
10. Taylor KL, Hadgkiss EJ, Jelinek GA, et al. Lifestyle factors, demographics and medications associated with depression risk in an international sample of people with multiple sclerosis. BMC Psychiatry. 2014;14:327.

11. Robens S, Gunn H, Kemp A, Fox E, Freeman J. Social isolation amongst people severely affected by multiple sclerosis. Way Ahead. 2015;19:8-10.

12. Solari A, Acquarone N, Pucci E, et al. Communicating the diagnosis of multiple sclerosis-a qualitative study. Mult Scler. 2007;13:763-9.

13. Atreja A, Mehta N, Miller D, et al. One size does not fit all: using qualitative methods to inform the development of an Internet portal for multiple sclerosis patients. AMIA Annu Symp Proc. 2005;2005:16-20.

14. Boyd DM, Ellison NB. Social network sites: definition, history, and scholarship. J Comput Commun. 2007;13:210-30.

15. Laranjo L, Arguel A, Neves AL, et al. The influence of social networking sites on health behavior change: a systematic review and meta-analysis. J Am Med Inform Assoc. 2015;22:243-56.

16. Preece J. Online communities: supporting sociability, designing usability. Hoboken: Wiley; 2000. p. $1-468$.

17. Bob Willmot. Bob's bum knees. http://www. willmot.com/knees/. Accessed 20 Sept 2017.

18. Pew Research Center. Social networking fact sheet. http://www.pewinternet.org/fact-sheets/social-net working-fact-sheet/. Accessed 30 July 2017.

19. Perrin A, Duggan M. Americans' internet access: 2000-2015. Pew Research Center 2015:1-13. http:// www.pewinternet.org/2015/06/26/americans-inter net-access-2000-2015/. Accessed 30 July 2017.

20. Bayer HealthCare Pharmaceuticals, Microsoft, National Multiple Sclerosis Society. New survey finds technology plays a critical role in the lives of people with multiple sclerosis yet many are not using it to overcome disease-related challenges. http://multivu.prnewswire.com/mnr/bayer/30325/. Accessed 30 July 2017.

21. Haase R, Schultheiss T, Kempcke R, Thomas K, Ziemssen $T$. Use and acceptance of electronic communication by patients with multiple sclerosis: a multicenter questionnaire study. J Med Internet Res. 2012;14:e135.

22. Marrie RA, Salter AR, Tyry T, Fox RJ, Cutter GR. Preferred sources of health information in persons with multiple sclerosis: degree of trust and information sought. J Med Internet Res. 2013;15:e67.
23. Paul L, Tallner A, Kos D, Renom M. Telerehabilitation to support behaviour change in MS. Way Ahead. 2015;19:13-5.

24. Multiple Sclerosis International Federation. MS in focus. Information, technology and MS. http:// www.msif.org/wp-content/uploads/2014/09/MS-infocus-23-Information-and-communication-English. pdf. Accessed 30 July 2017.

25. Facebook. Facebook newsroom. http://newsroom. fb.com/company-info/. Accessed 30 July 2017.

26. Twitter. Twitter usage: company facts. https://about. twitter.com/company. Accessed 30 July 2017.

27. Solari A, Martinelli V, Trojano M, et al. An information aid for newly diagnosed multiple sclerosis patients improves disease knowledge and satisfaction with care. Mult Scler. 2010;16:1393-405.

28. Colombo C, Mosconi P, Confalonieri P, et al. Web search behavior and information needs of people with multiple sclerosis: focus group study and analysis of online postings. Interact $\mathrm{J}$ Med Res. 2014;3:e12.

29. MultipleSclerosis.net. Health information and the Internet: where do you fit in? 2016. https:// multiplesclerosis.net/infographic/you-health-andthe-internet/. Accessed 31 July 2017.

30. Biogen. State of MS: global survey factsheet. https:// www.biogen.com/content/dam/corporate/en_us/ pdfs/StateofMS_FactSheet_9SEP2014.pdf. Accessed 30 July 2017.

31. Hay MC, Strathmann C, Lieber E, Wick K, Giesser B. Why patients go online: multiple sclerosis, the internet, and physician-patient communication. Neurologist. 2008;14:374-81.

32. Nielsen AS, Halamka JD, Kinkel RP. Internet portal use in an academic multiple sclerosis center. J Am Med Inform Assoc. 2012;19:128-33.

33. Wardell L, Hum S, Laizner AM, Lapierre Y. Multiple sclerosis patients' interest in and likelihood of using online health-care services. Int J MS Care. 2009;11:79-89.

34. Baker LM, Connor JJ. Physician-patient communication from the perspective of library and information science. Bull Med Libr Assoc. 1994;82:36-42.

35. Houston TK, Allison JJ. Users of Internet health information: differences by health status. J Med Internet Res. 2002;4:E7.

36. Lejbkowicz I, Paperna T, Stein N, Dishon S, Miller A. Internet usage by patients with multiple sclerosis: 
implications to participatory medicine and personalized healthcare. Mult Scler Int. 2010;2010:640749.

37. Rice RE. Influences, usage, and outcomes of Internet health information searching: multivariate results from the Pew surveys. Int J Med Inform. 2006;75:8-28.

38. Stewart DC, Sullivan TJ. Illness behavior and the sick role in chronic disease. The case of multiple sclerosis. Soc Sci Med. 1982;16:1397-404.

39. Marrie RA, Salter A, Tyry T, Fox RJ, Cutter GR. Health literacy association with health behaviors and health care utilization in multiple sclerosis: a cross-sectional study. Interact J Med Res. 2014;3:e3.

40. Berkman ND, Sheridan SL, Donahue KE, Halpern DJ, Crotty K. Low health literacy and health outcomes: an updated systematic review. Ann Intern Med. 2011;155:97-107.

41. Dizon DS, Graham D, Thompson MA, et al. Practical guidance: the use of social media in oncology practice. J Oncol Pract. 2012;8:e114-24.

42. Royal College of General Practitioners. Social media highway code. http://www.rcgp.org.uk/ /media/ files/policy/a-z-policy/rcgp-social-media-highwaycode.ashx. Accessed 30 July 2017.

43. Ventola CL. Social media and health care professionals: benefits, risks, and best practices. Pharm Ther. 2014;39:491-520.

44. George DR, Rovniak LS, Kraschnewski JL. Dangers and opportunities for social media in medicine. Clin Obstet Gynecol. 2013;56:453-62.

45. Kopke S, Solari A, Khan F, Heesen C, Giordano A. Information provision for people with multiple sclerosis. Cochrane Database Syst Rev. 2014;4:CD008757.

46. Rieckmann P, Boyko A, Centonze D, et al. Achieving patient engagement in multiple sclerosis: a perspective from the multiple sclerosis in the 21st Century Steering Group. Mult Scler Relat Disord. 2015;4:202-18.

47. Narayanaswami P, Gronseth G, Dubinsky R, et al. The impact of social media on dissemination and implementation of clinical practice guidelines: a longitudinal observational study. J Med Internet Res. 2015;17:e193.

48. Gagnon K, Sabus C. Professionalism in a digital age: opportunities and considerations for using social media in health care. Phys Ther. 2015;95:406-14.
49. Langhorne A, Thomas P, Kolaczkowski L. Untangling the web of e-Health: multiple sclerosis patients' perceptions of online health information, information literacy, and the impact on treatment decision making. In: Ozok AA, Zaphiris P, editors. Lecture notes in computer science, online communities and social computing. New York: Springer; 2013. p. 304-12.

50. Wheelchair Kamikaze. The rants, ruminations, and reflections of a mad MStery patient. http://www. wheelchairkamikaze.com/. Accessed 30 July 2017.

51. PatientsLikeMe. Social media. http://news. patientslikeme.com/social-media. Accessed 31 July 2017.

52. Ramagopalan S, Wasiak R, Cox AP. Using Twitter to investigate opinions about multiple sclerosis treatments: a descriptive, exploratory study. F1000Research. 2014;3:216.

53. Risson V, Saini D, Bonzani I, Huisman A, Olson M. Patterns of treatment switching in multiple sclerosis therapies in US patients active on social media: application of social media content analysis to health outcomes research. J Med Internet Res. 2016;18:e62.

54. Gueguen A, Maillart E, Gallice T, Allaf B. Evaluation of French-language internet sites dealing with multiple sclerosis. Mult Scler J Exp Transl Clin. 2016;2. https://doi.org/10.1177/2055217316652419.

55. Ghahari S, Forwell SJ. Social media representation of chronic cerebrospinal venous insufficiency intervention for multiple sclerosis. Int J MS Care. 2016;18:49-57.

56. Hill S, Filippini G, Synnot A, et al. Presenting evidence-based health information for people with multiple sclerosis: the IN-DEEP project protocol. BMC Med Inform Decis Mak. 2012;12:20.

57. Lavorgna L, De Stefano M, Buonanno B, et al. Social media and multiple sclerosis: an Italian experience. Neurology. 2014;82(Suppl 10):S49.004.

58. Lavorgna L, Russo A, De Stefano M, et al. Healthrelated coping and social interaction in people with multiple sclerosis supported by a social network: pilot study with a new methodological approach. Interact J Med Res. 2017;6:e10. 